\title{
Higher Serum Triglyceride Can Predict Recurrent Coronary Revascularization Events in Patients Undergoing Percutaneous Coronary Intervention With Baseline LDL-C<55mg/dl
}

\section{Xiaojuan Fan}

First Affiliated Hospital of Xi'an Jiaotong University

\section{Xiaoke Wang}

First Affiliated Hospital of Xi'an Jiaotong University

Jianqing She

First Affiliated Hospital of Xi'an Jiaotong University

Xiaoqian Niu

First Affiliated Hospital of Xi'an Jiaotong University

Yongbai Luo

First Affiliated Hospital of Xi'an Jiaotong University

Wen Xi

First Affiliated Hospital of Xi'an Jiaotong University

Tao zheng

First Affiliated Hospital of Xi'an Jiaotong University

Yue Wu ( $\nabla$ yue.wu@xjtu.edu.cn )

First Affiliated Hospital of Xi'an Jiaotong University

\section{Research Article}

Keywords: Triglyceride, low-density lipoprotein cholesterol, recurrent coronary revascularization

Posted Date: February 25th, 2022

DOI: https://doi.org/10.21203/rs.3.rs-1385123/v1

License: (c) (i) This work is licensed under a Creative Commons Attribution 4.0 International License. Read Full License 


\section{Abstract}

Background: Patients with low baseline low-density lipoprotein cholesterol (LDL-C) but experiencing recurrent coronary revascularization events have been rarely investigated.

Methods: In this retrospective study, we enrolled patients undergoing percutaneous coronary intervention (PCl) with baseline LDL-C $<55 \mathrm{mg} / \mathrm{dl}$ at the First Affiliated Hospital of Xi'an Jiaotong University between January and December 2017. Subsequent ischemia-driven revascularization events and all-cause death were documented during a 4-year follow-up. Cox analysis was used to evaluate the association between baseline clinical characteristics and long-term events.

Results: Among 388 patients (mean age 63 years; 79.1\% male) enrolled, 32 patients underwent recurrent revascularization events, and 38 patients occurred all-cause death. After adjustment for age, diabetes mellitus, multi-vessel disease and lipoprotein(a), multivariate Cox analysis showed that baseline serum triglyceride (TG) (HR=1.691, 95\% Cl: 1.178-2.428, $p=0.004)$ was an independent predictor of recurrent coronary revascularization events. Kaplan-Meier analysis revealed that a higher TG level $(\geq 1.17 \mathrm{mmol} / \mathrm{L}$, determined by ROC curve) was associated with increased risk of recurrent revascularization events than lower TG level $(<1.17 \mathrm{mmol} / \mathrm{L})(p=0.021)$. Female ( $\mathrm{HR}=2.647,95 \% \mathrm{Cl}: 1.350-5.190, p=0.005)$ and previous atrial fibrillation ( $\mathrm{HR}=3.163,95 \% \mathrm{Cl}: 1.403-7.132, p=0.006)$ were associated with increased risk of allcause death in this patient group.

Conclusions: For patients undergoing PCl with baseline LDL-C $<55 \mathrm{mg} / \mathrm{dl}$, higher baseline TG can predict recurrent coronary revascularization events.

\section{Introduction}

Low-density lipoprotein cholesterol (LDL-C) is one of the most critical risk factors for atherosclerotic cardiovascular disease (ASCVD). Consistent evidence proves that LDL-C lowering provides incremental cardiovascular benefits. A new class of lipid-lowering drug, PCSK9 inhibitor, can strongly reduce LDL-C to an extremely low level and bring further cardiovascular benefits. So the current guidelines have updated and set a new LDL-C goal of $<55 \mathrm{mg} / \mathrm{dl}$ in patients at very high risk of ASCVD for secondary prevention[1].

However, regardless of which lipid-lowering agent is used, the clinical benefits depend on the baseline LDL-C level and the absolute magnitude of LDL-C reduction[2]. The higher the baseline LDL-C is, the more benefits derived from lipid-lowering therapy. Cardiovascular benefits from intensified lipid-lowering therapy are expected less in those with baseline LDL-C $<100 \mathrm{mg} / \mathrm{dl}[3,4]$. Serial intravascular ultrasound analysis also indicates that statin therapy is less effective in inducing coronary plaque regression in patients with low LDL-C[5]. A challenging problem in clinical practice is that a group of patients develop ASCVD despite low baseline LDL-C and continue experiencing recurrent ischemic events even under statin therapy[6-8]. In addition to LDL-C, what other risk factors are involved in this specific patient group have been scarcely studied. Therefore, our study aimed to explore which baseline risk factor could be 
associated with recurrent revascularization events in patients undergoing percutaneous coronary intervention (PCl) with baseline LDL-C $<55 \mathrm{mg} / \mathrm{dl}$.

\section{Methods}

\section{Population}

This is a retrospective cohort study. Consecutive patients with coronary artery disease (CAD) undergoing PCl from January to December 2017 at the First Affiliated Hospital of Xi'an Jiaotong University were screened. Patients with successful PCl and baseline LDL-C $<55 \mathrm{mg} / \mathrm{dl}$ were included in our study. The exclusion criteria were as follows: (1) no statin therapy at discharge; (2) occurring in-hospital death; (3) the occurrence of recurrent revascularization due to withdrawl of anti-platelet or statin treatment; (4) loss of follow-up. The study was approved by the ethics committee of our institution. Written informed consent was waived due to a retrospective design. The study protocol conforms to the ethical guidelines of the 1975 Declaration of Helsinki.

Baseline clinical information was collected from standard medical records, including demographic data, diagnosis at presentation, detailed previous histories. Fasting blood tests including alanine aminotransferase (ALT), serum albumin (ALB), serum creatinine (CRE), glycated hemoglobin A1c (HbA1c), LDL-C, high-density lipoprotein cholesterol (HDL-C), triglyceride (TG), total cholesterol (TC), and lipoprotein(a) were collected. Platelet (PLT) and hemoglobin tested at admission were recorded. Left ventricular ejection fraction (LVEF) mearsured by simpson's method was collected.

The manifestations of coronary angiography (CAG) were characterized by the affected number of 3major epicardial arteries (stenosis of the lumen diameter $>50 \%$ ), defined as 1-vessel, 2-vessel, and multivessel diseases.

\section{Clinical outcomes}

During a 4-year follow-up, all-cause death, acute myocardial infarction (AMI), angina, any recurrent coronary revascularization (unplanned $\mathrm{PCl}$ or coronary artery bypass graft (CABG)), and stroke were documented. The endpoint was any unplanned coronary revascularization due to recurrent ischemic events and all-cause death. All follow-up information was obtained in April 2021 by telephone interview or by checking patient visits to the outpatient clinic or readmission medical records.

\section{Statistical analysis}

Patients were stratified into 2 groups according to the occurrence of recurrent revascularization events. Continuous normally distributed data were presented as mean with standard deviation, and non-normally distributed data were shown as median with 25th and 75th percentiles; Unpaired t-test and Mann-Whitney 
U test were used as appropriate. For discrete variables, differences were expressed as counts and percentages and were analyzed with chi-square or Fisher exact test.

Cox regression analysis was used to estimate the adjusted hazard ratios (HR) and 95\% confidence intervals $(\mathrm{Cl})$ for revascularization events and all-cause death predictors. When analyzing the independent predictors of recurrent revascularization, we put the variables with $p \leq 0.2$ obtained in the univariate Cox regression (including age, TG, lipoprotein(a)) and established risk factors (diabetes mellitus and multivessel disease) into stepwise forward selection multivariate Cox analysis. Kaplan-Meier analysis was used to compare the cumulative incidence of recurrent revascularization events by log-rank test.

When analyzing the independent predictors of all-cause death, we put the variables with $p \leq 0.1$ obtained in the univariate Cox regression (including age, sex, hemoglobin, and history of atrial fibrillation and multivessel disease) into the multivariate analysis.

A two-tailed $p \leq 0.05$ was considered statistically significant. Statistical analysis involved the use of SPSS v25.0 (SPSS Inc., Chicago, IL).

\section{Results}

\section{Study population}

From January to December 2017, a total of 2955 patients undergoing successful PCl and receiving stating therapy at discharge were screened; 2530 patients with LDL-C $\geq 55 \mathrm{mg} / \mathrm{dl}$ were excluded, and the remaining 425 patients $(14.3 \%)$ with $\mathrm{LDL}-\mathrm{C}<55 \mathrm{mg} / \mathrm{dl}$ and statin therapy at discharge were enrolled. 1 patient experiencing recurrent $\mathrm{PCl}$ due to withdrawal of statin was excluded;36 patients were lost to follow-up. At last, 388 patients were included in this study (Fig. 1). At presentation, 287 patients (74.0\%) were diagnosed with unstable angina (UA), 63 patients (16.2\%) with ST-elevation myocardial infarction (STEMI), 29 patients (7.5\%) with non-ST elevation myocardial infarction (NSTEMI) and 9 patients (2.3\%) with ischemic cardiomyopathy.

\section{Follow-up clinical events}

During a 4-year follow-up, 32 patients (8.2\%) underwent recurrent ischemic-driven revascularization procedures (29 PCl and $3 \mathrm{CABG}$ ), and 38 patients (9.8\%) occurred all-cause death. The comparison of clinical, laboratory, angiographic characteristics and follow-up information between the revascularization group and the non-revascularization group were listed in Table 1. Patients in the revascularization group presented higher serum CRE $(p=0.03)$, more multi-vessel disease $(p=0.03)$, and more events of AMI and angina in follow-up (both $p<0.001$ ). 
Table 1

Comparison of clinical, laboratory, angiographic characteristics and clinical outcomes between two groups.

\begin{tabular}{|c|c|c|c|c|}
\hline & $\begin{array}{l}\text { The Whole } \\
(n=388)\end{array}$ & $\begin{array}{l}\text { Non-revascularization } \\
\text { group } \\
(n=356)\end{array}$ & $\begin{array}{l}\text { Revascularization } \\
\text { group } \\
(n=32)\end{array}$ & $\mathbf{P}$ \\
\hline Male, n (\%) & $307(79.1 \%)$ & $280(78.7 \%)$ & $27(84.4 \%)$ & 0.431 \\
\hline Age, years & $63 \pm 10$ & $63 \pm 10$ & $64 \pm 10$ & 0.895 \\
\hline Presentation, n (\%) & & & & 0.405 \\
\hline UA & $287(74.0 \%)$ & $261(73.3 \%)$ & $26(81.3 \%)$ & \\
\hline STEMI & $63(16.2 \%)$ & $58(16.3 \%)$ & $5(15.6 \%)$ & \\
\hline NSTEMI & $29(7.5)$ & $28(7.9 \%)$ & $1(3.1 \%)$ & \\
\hline Ischemic cardiomyopathy & $9(2.3)$ & $9(2.5 \%)$ & $0(0 \%)$ & \\
\hline \multicolumn{5}{|l|}{ History of disease, $n(\%)$} \\
\hline $\mathrm{AF}$ & $24(6.2 \%)$ & $23(6.5 \%)$ & $1(3.1 \%)$ & 0.708 \\
\hline $\mathrm{OMI}$ & $51(13.1 \%)$ & $47(13.2 \%)$ & $4(12.5 \%)$ & 1 \\
\hline Previous $\mathrm{PCl}$ & $26(6.7 \%)$ & $24(6.7 \%)$ & $2(6.3 \%)$ & 0.998 \\
\hline $\mathrm{HP}$ & $242(62.4 \%)$ & $221(62.1 \%)$ & $21(65.6 \%)$ & 0.547 \\
\hline DM & $145(37.4 \%)$ & 132(37.1\%) & $13(40.6 \%)$ & 0.693 \\
\hline Previous stroke & $19(4.9 \%)$ & $19(5.3 \%)$ & $0(0 \%)$ & 0.387 \\
\hline \multicolumn{5}{|l|}{ Laboratory test } \\
\hline$A L T, U / L$ & $25(16-38)$ & $25(16-38)$ & $29(19-47)$ & 0.223 \\
\hline ALB, g/L & $\begin{array}{l}39.2(36.6- \\
41.8)\end{array}$ & $39.2(36.7-41.7)$ & $39.1(34.9-42.3)$ & 0.739 \\
\hline CRE, mmol/L & $70(60-83)$ & $69(59-82)$ & $77(67-86)$ & 0.030 \\
\hline $\mathrm{HbA} 1 \mathrm{c}, \mathrm{mmol} / \mathrm{L}$ & $5.9(5.4-6.8)$ & $5.8(5.4-6.8)$ & $6.2(5.4-7.3)$ & 0.261 \\
\hline $\mathrm{HB}, \mathrm{g} / \mathrm{L}$ & $\begin{array}{l}132(122- \\
140)\end{array}$ & $132(122-140)$ & $131(120-143)$ & 0.948 \\
\hline
\end{tabular}

UA, unstable angina; STEMI, ST-segment elevation myocardial infarction; NSTEMI, non-ST-segment elevation myocardial infarction; $\mathrm{AF}$, atrial fibrillation; $\mathrm{OMI}$, old myocardial infarction; $\mathrm{PCl}$, percutaneous coronary intervention; HP, hypertension; DM, diabetes mellitus; ALT, alanine aminotransferase; ALB, serum albumin; $\mathrm{CRE}$, creatinine; $\mathrm{HbA} 1 \mathrm{c}$, glycated hemoglobin $\mathrm{A} 1 \mathrm{c} ; \mathrm{HB}$, hemoglobin; PLT, platelet; $\mathrm{TC}$, total cholesterol; TG, triglyceride; HDL-C, high-density lipoprotein cholesterol; LDL-C, low-density lipoprotein cholesterol; LVEF, left ventricular ejection fraction; AMI, acute myocardial infarction. 


\begin{tabular}{|c|c|c|c|c|}
\hline & $\begin{array}{l}\text { The Whole } \\
(n=388)\end{array}$ & $\begin{array}{l}\text { Non-revascularization } \\
\text { group } \\
(n=356)\end{array}$ & $\begin{array}{l}\text { Revascularization } \\
\text { group } \\
(n=32)\end{array}$ & $P$ \\
\hline $\mathrm{PLT}, 10^{\wedge} 9 / \mathrm{L}$ & $\begin{array}{l}170(137- \\
210)\end{array}$ & $170(136-210)$ & $175(146-219)$ & 0.409 \\
\hline $\mathrm{TC}, \mathrm{mmol} / \mathrm{L}$ & $\begin{array}{l}2.57(2.37- \\
2.76)\end{array}$ & $2.56(2.37-2.76)$ & $2.63(2.46-2.73)$ & 0.402 \\
\hline $\mathrm{TG}, \mathrm{mmol} / \mathrm{L}$ & $\begin{array}{l}0.99(0.77- \\
1.33)\end{array}$ & $0.97(0.76-1.29)$ & $1.24(0.83-1.43)$ & 0.078 \\
\hline $\mathrm{HDL}-\mathrm{C}, \mathrm{mmol} / \mathrm{L}$ & $\begin{array}{l}0.83(0.72- \\
0.95)\end{array}$ & $0.83(0.72-0.95)$ & $0.82(0.68-0.96)$ & 0.845 \\
\hline LDL-C, mmol/L & $\begin{array}{l}1.21(1.07- \\
1.32)\end{array}$ & $1.21(1.07-1.32)$ & $1.21(1.02-1.35)$ & 0.780 \\
\hline Lipoprotein(a), mg/L & $\begin{array}{l}115(59- \\
220)\end{array}$ & $113(58-219)$ & $145(75-229)$ & 0.354 \\
\hline LVEF, \% & $63(53-69)$ & $63(53-69)$ & $63(50-71)$ & 0.943 \\
\hline $\begin{array}{l}\text { Angiographic } \\
\text { characteristics, n (\%) }\end{array}$ & & & & 0.030 \\
\hline 1-vessel & $58(14.9 \%)$ & $57(16.0 \%)$ & $1(3.1 \%)$ & \\
\hline 2-vessel & $109(28.1 \%)$ & $102(28.7 \%)$ & $7(21.9 \%)$ & \\
\hline multi-vessel & $221(575 \%)$ & $197(55.3 \%)$ & $24(75.0 \%)$ & \\
\hline \multicolumn{5}{|l|}{ Follow-up, n (\%) } \\
\hline All-cause death & $38(9.8 \%)$ & $38(10.7 \%)$ & $0(0 \%)$ & 0.058 \\
\hline AMI & $11(2.8 \%)$ & $0(0 \%)$ & $11(34.4 \%)$ & $\begin{array}{l}< \\
0.001\end{array}$ \\
\hline Angina & $70(18 \%)$ & $49(13.8 \%)$ & $21(65.6 \%)$ & $\begin{array}{l}<.001 \\
0.001\end{array}$ \\
\hline Stroke & $5(1.3 \%)$ & $5(1.4 \%)$ & $0(0 \%)$ & 1 \\
\hline \multicolumn{5}{|c|}{$\begin{array}{l}\text { UA, unstable angina; STEMI, ST-segment elevation myocardial infarction; NSTEMI, non-ST-segment } \\
\text { elevation myocardial infarction; AF, atrial fibrillation; OMI, old myocardial infarction; PCI, percutaneous } \\
\text { coronary intervention; HP, hypertension; DM, diabetes mellitus; ALT, alanine aminotransferase; ALB, } \\
\text { serum albumin; CRE, creatinine; HbA1c, glycated hemoglobin A1c; HB, hemoglobin; PLT, platelet; TC, } \\
\text { total cholesterol; TG, triglyceride; HDL-C, high-density lipoprotein cholesterol; LDL-C, low-density } \\
\text { lipoprotein cholesterol; LVEF, left ventricular ejection fraction; AMI, acute myocardial infarction. }\end{array}$} \\
\hline
\end{tabular}

Predictors of recurrent revascularization and all-cause death 
Table 2 lists the results of univariate Cox analysis for recurrent revascularization events and all-cause death.

Table 2

Univariate Cox regression for predictors of recurrent revascularization and all-cause death

\begin{tabular}{|lllllll|}
\hline \multicolumn{5}{|c}{ Recurrent revascularization } & \multicolumn{3}{l}{ All-cause death } \\
\hline Variables & HR & $95 \%$ Cl & P value & HR & $95 \%$ Cl & P value \\
\hline Age & 0.972 & $0.944-1.001$ & 0.055 & 1.035 & $0.996-1.076$ & 0.083 \\
\hline Female & 0.598 & $0.229-1.561$ & 0.293 & 2.374 & $1.226-4.598$ & 0.010 \\
\hline History of AF & 0.320 & $0.043-2.355$ & 0.263 & 2.700 & $1.215-5.999$ & 0.015 \\
\hline History of OMI & 0.917 & $0.315-2.699$ & 0.873 & 0.845 & $0.297-2.400$ & 0.751 \\
\hline History of HP & 1.069 & $0.512-2.229$ & 0.859 & 0.875 & $0.448-1.709$ & 0.697 \\
\hline History of DM & 1.081 & $0.516-2.226$ & 0.837 & 1.211 & $0.616-2.382$ & 0.579 \\
\hline Previous PCI & 1.938 & $0.956-3.927$ & 0.366 & 0.670 & $0.324-1.386$ & 0.281 \\
\hline ALT & 0.999 & $0.995-1.002$ & 0.466 & 1.000 & $0.999-1.002$ & 0.434 \\
\hline CRE & 1.001 & $0.990-1.012$ & 0.897 & 1.006 & $0.998-1.015$ & 0.136 \\
\hline HbA1c & 0.990 & $0.781-1.255$ & 0.936 & 1.109 & $0.912-1.350$ & 0.300 \\
\hline HB & 1.014 & $0.994-1.034$ & 0.268 & 0.980 & $0.964-0.996$ & 0.016 \\
\hline PLT & 1.001 & $0.995-1.007$ & 0.771 & 1.003 & $0.997-1.008$ & 0.365 \\
\hline TC & 1.647 & $0.497-5.473$ & 0.415 & 1.626 & $0.566-4.665$ & 0.366 \\
\hline TG & 1.691 & $1.178-2.428$ & 0.004 & 0.745 & $0.371-1.495$ & 0.407 \\
\hline HDL-C & 0.682 & $0.133-3.500$ & 0.647 & 2.521 & $0.607-10.467$ & 0.203 \\
\hline Lipoprotein(a) & 1.002 & $0.999-1.004$ & 0.181 & 1.001 & $0.998-1.003$ & 0.566 \\
\hline LVEF & 0.999 & $0.969-1.031$ & 0.964 & 0.994 & $0.966-1.022$ & 0.668 \\
\hline Multi-vessel disease & 1.411 & $0.628-3.170$ & 0.404 & 0.467 & $0.241-0.901$ & 0.023 \\
\hline AF, atrial fibrillation; OMI, old myocardial infarction; HP, hypertension; DM, diabetes mellitus; PCl, \\
percutaneous coronary intervention; ALT, alanine aminotransferase; CRE, creatinine; HbA1C, glycated \\
hemoglobin A1C; HB, hemoglobin; PLT, platelet; TC, total cholesterol; TG, triglyceride; HDL-C, high- \\
density lipoprotein cholesterol; LVEF, left ventricular ejection fraction; & & \\
\hline
\end{tabular}

Univariate Cox regression showed only TG was statistically associated with recurrent revascularization events ( $\mathrm{HR}=1.691,95 \% \mathrm{Cl}: 1.178-2.428, p=0.004)$. When analyzing the independent predictors for recurrent revascularization events, we put the variables with $p \leq 0.2$ obtained in the univariate analysis 
(including age, lipoprotein(a), TG), and established risk factors (diabetes mellitus and multi-vessel disease) into multivariate Cox analysis. As a result, baseline TG (HR = 1.691, 95\% Cl: 1.178-2.428, $p=$ 0.004 ) was still the only independent predictor for recurrent revascularization in patients undergoing $\mathrm{PCl}$ with baseline LDL-C $<55 \mathrm{mg} / \mathrm{dl}$.

Since there is no established cut-point for TG, we used receiver operating characteristic curve (ROC) analysis to acquire the optimal cut-off value. Patients were further divided into two groups: higher TG group ( $\geq 1.17 \mathrm{mmol} / \mathrm{L}$ ) and lower TG group ( $<1.17 \mathrm{mmol} / \mathrm{L})$. Kaplan-Meier analysis demonstrated that a higher TG level was associated with a higher risk of recurrent revascularization events than a lower TG level ( $p=0.021$ by log-rank test) (Fig. 2).

When analyzing the potential predictors of all-cause death, we put the variables with $p \leq 0.1$ obtained in the univariate Cox regression (including age, sex, hemoglobin, history of atrial fibrillation, and multi-vessel disease) into the multivariate analysis. The results showed that female $(\mathrm{HR}=2.647,95 \% \mathrm{Cl}: 1.350-5.190$, $p=0.005)$ and previous atrial fibrillation ( $\mathrm{HR}=3.163,95 \% \mathrm{Cl}: 1.403-7.132, p=0.006)$ were associated higher risk of all-cause death in patients undergoing $\mathrm{PCl}$ with baseline $\mathrm{LDL}<55 \mathrm{mg} / \mathrm{dl}$.

\section{Discussion}

The main findings of the current study are as follows: 1 ) despite baseline LDL-C $<55 \mathrm{mg} / \mathrm{dl}$ and statin therapy, the risk of recurrent ischemic-driven revascularization events in patients undergoing $\mathrm{PCl}$ remained high (8.2\%); 2) baseline TG was an independent predictor of recurrent revascularization events in those patients;3) female and previous atrial fibrillation were associated with a higher risk of all-cause death in those patients.

An LDL-C $<70 \mathrm{mg} / \mathrm{dl}$ was the previous target goal in secondary prevention for ASCVD patients before the PCSK-9 inhibitor came out. But ASCVD can occur in individuals even with low LDL-C levels. AMI patients with baseline LDL-C $<70 \mathrm{mg} / \mathrm{dl}$ occupied $7.1 \%$ in the KAMIR study[9]. In the TERCET study, the proportion rose to $20.7 \%$ among patients with acute coronary syndrome (ACS) [10]. In a PCI registry study, the ratio reached $41.9 \%[11]$. Even with low baseline LDL-C, statin therapy improves clinical prognosis [6-9]. But the benefit is less prominent as compared with high LDL-C, and recurrent vascular events continue to occur[3, 4], which suggests other risk factors, rather than LDL-C, are involved in atherosclerosis progression for those patients.

Numerous studies have shown an association between baseline serum TG and ASCVD. Elevated TG is related not only to subclinical atherosclerosis and vascular inflammation despite normal LDL-C[12] but also equally to residual cardiovascular risk among patients receiving statin therapy[13], especially those with diabetes mellitus[14]. Among ACS patients with all baseline levels of LDL-C and treated effectively with statins, studies have found TG was associated with recurrent ischemic events after ACS[15, 16]. Our study focused on patients with baseline LDL-C $<55 \mathrm{mg} / \mathrm{dl}$ and got consistent results. 
The AHA suggests optimal fasting TG level should be defined as $<1.2 \mathrm{mmol} / \mathrm{L}[17]$. It points out that TGrich lipoproteins and the remnants accumulate in the plasma when $T G>1.2 \mathrm{mmol} / \mathrm{L}$, while efficient lipolysis results in limited accumulation of remnant particles when $T G<1.2 \mathrm{mmol} / \mathrm{L}[18]$. Our study used ROC analysis to acquire a similar cut-off value of $1.17 \mathrm{mmol} / \mathrm{L}$ and found that patients with $T G \geq 1.17$ $\mathrm{mmol} / \mathrm{L}$ had a statistically higher risk of recurrent revascularization than TG $<1.17 \mathrm{mmoL} / \mathrm{L}$. The 2019 ESC/EAS guideline suggests that TG-lowering drugs could be prescribed in high-risk patients only when $\mathrm{TG}$ is $>2.3 \mathrm{mmol} / \mathrm{L}[1]$. The recent REDUCE-IT trial demonstrated that icosapent ethyl, one TG-lowering agent, could reduce the need for first and subsequent coronary revascularizations in statin-treated patients with LDL-C $<100 \mathrm{mg} / \mathrm{dl}$ and fasting $T G>1.52 \mathrm{mmol} / \mathrm{L}[19,20]$. The optimal cut-point for initiating TG-lowering therapy in patients with different LDL-C level may need further exploration.

Although higher TG was related to a higher risk of revascularization, it was not associated with all-cause death in our study. This conclusion was not consistent with previous research[21], which could be explained by the different baseline characteristics of the enrolled patients. Patients with low baseline LDL-C usually present worse clinical profiles, such as more comorbidities and older age[10,22]. Our study showed that in patients with LDL-C $<55 \mathrm{mg} / \mathrm{dl}$, female and previous atrial fibrillation was associated with a higher risk of all-cause death.

\section{Conclusion}

In this study, we investigated why ischemia-driven revascularization events recurrently occurred in patients with LDL-C $<55 \mathrm{mg} / \mathrm{dl}$ and found that baseline TG was an independent risk factor in those patients. Except for statin therapy, TG-lowering agents may yield additional cardiovascular benefits in patients with low LDL-C but high TG levels.

\section{Limitations}

The present study had some limitations. First, patients with baseline LDL-C $<55 \mathrm{mg} / \mathrm{dl}$ had two situations: receiving statin therapy or being born this way, which could potentially affect the results concluded in our study. But if patients can easily reach the target goal under statin therapy but continue to suffer recurrent events, they should be paid equal attention. Second, in addition to TG, other risk factors are also involved in the residual cardiovascular risk, such as C-reactive protein. We could not study it because of data deficiency. Third, the study was a retrospective cohort design with inherent prejudice.

\section{Abbreviations}

LDL-C: low-density lipoprotein cholesterol; PCI: percutaneous coronary intervention; TG: triglyceride; ASCVD: atherosclerotic cardiovascular disease; CAD: coronary artery disease; ALT: alanine aminotransferase; ALB: albumin; CRE: creatinine; HbA1c: glycated hemoglobin A1c; HDL-C: high-density lipoprotein cholesterol; TC: total cholesterol; PLT: platelet; LVEF: left ventricular ejection fraction; CAG: coronary angiography; AMI: acute myocardial infarction; CABG: coronary artery bypass graft; HR: hazard 
ratios; Cl: confidence intervals; UA: unstable angina; STEMI: ST-elevation myocardial infarction; NSTEMI: non-ST elevation myocardial infarction;

\section{Declarations}

\section{Ethics approval and consent to participate}

The study was approved by the ethics committee of the First Affiliated Hospital of Xi'an Jiaotong University. Written informed consent was waived due to a retrospective design.

\section{Consent for publication}

All authors signed the informed consent.

\section{Availability of data and materials}

The datasets in the current study are available from the corresponding author on reasonable request.

\section{Competing interests}

The authors declare no competing interests.

\section{Funding}

This study was supported by the National Key R\&D Program of China (2019YFA0802300, 2021YFA1301200), the National Natural Science Foundation of China (81970351, 82170464), Key Research and Development Program of Shaanxi (No.2020SF-253), Central University Basic Science Foundation of China (119132971000056); and the Clinical Research Award of the First Affiliated Hospital of Xi'an Jiaotong University, China (No. XJTU1AF-CRF-2019-011).

\section{Author Contributions}

Conceptualization, Xiaojuan Fan and Yue Wu; data collection and analysis, Xiaojuan Fan, Xiaoqian Niu, Yongbai Luo, Xiaoke Wang, Wen Xi, Tao Zheng; writing-original draft preparation, Xiaojuan Fan; writingreview and editing, Xiaoke Wang, Yue Wu; supervision, Jianqing She, Yue Wu. All authors have read and agreed to the published version of the manuscript.

\section{Acknowledgements}

N/A.

\section{References}

1. Mach F, Baigent C, Catapano AL, Koskinas KC, Casula M, Badimon L, Chapman MJ, De Backer GG, Delgado V, Ference BA et al: 2019 ESC/EAS Guidelines for the management of dyslipidaemias: lipid 
modification to reduce cardiovascular risk. European heart journal 2020, 41(1):111-188.

2. Navarese EP, Andreotti F, Raggi P, Kolodziejczak M, Buffon A, Bliden K, Tantry U, Kubica J, Sardella G, Lauten A et al: Baseline low-density lipoprotein cholesterol to predict the extent of cardiovascular benefit from lipid-lowering therapies: a review. European heart journal Cardiovascular pharmacotherapy 2019, 5(1):47-54.

3. Robinson JG, Jayanna MB, Bairey Merz CN, Stone NJ: Clinical implications of the log linear association between LDL-C lowering and cardiovascular risk reduction: Greatest benefits when LDL-C $>100$ mg/dl. PloS one 2020, 15(10):e0240166.

4. Navarese EP, Robinson JG, Kowalewski M, Kolodziejczak M, Andreotti F, Bliden K, Tantry U, Kubica J, Raggi P, Gurbel PA: Association Between Baseline LDL-C Level and Total and Cardiovascular Mortality After LDL-C Lowering: A Systematic Review and Meta-analysis. Jama 2018, 319(15):15661579.

5. Wakabayashi K, Nozue T, Yamamoto S, Tohyama S, Fukui K, Umezawa S, Onishi Y, Kunishima T, Sato A, Miyake S et al: Efficacy of Statin Therapy in Inducing Coronary Plaque Regression in Patients with Low Baseline Cholesterol Levels. J Atheroscler Thromb 2016, 23(9):1055-1066.

6. Piao ZH, Jin L, Kim JH, Ahn Y, Kim YJ, Cho MC, Kim CJ, Kim HS, Liu B, Jeong MH: Benefits of Statin Therapy in Patients With Acute Myocardial Infarction With Serum Low-Density Lipoprotein Cholesterol $\leq \mathbf{5 0}$ mg/dl. The American journal of cardiology 2017, 120(2):174-180.

7. Leeper NJ, Ardehali R, deGoma EM, Heidenreich PA: Statin use in patients with extremely low lowdensity lipoprotein levels is associated with improved survival. Circulation 2007, 116(6):613-618.

8. Giugliano RP, Keech A, Murphy SA, Huber K, Tokgozoglu SL, Lewis BS, Ferreira J, Pineda AL, Somaratne R, Sever PS et al: Clinical Efficacy and Safety of Evolocumab in High-Risk Patients Receiving a Statin: Secondary Analysis of Patients With Low LDL Cholesterol Levels and in Those Already Receiving a Maximal-Potency Statin in a Randomized Clinical Trial. JAMA cardiology 2017, 2(12):1385-1391.

9. Lee KH, Jeong MH, Kim HM, Ahn Y, Kim JH, Chae SC, Kim YJ, Hur SH, Seong IW, Hong TJ et al: Benefit of early statin therapy in patients with acute myocardial infarction who have extremely low low-density lipoprotein cholesterol. Journal of the American College of Cardiology 2011, 58(16):1664-1671.

10. Dyrbus K, Gasior M, Desperak P, Nowak J, Osadnik T, Banach M: Characteristics of lipid profile and effectiveness of management of dyslipidaemia in patients with acute coronary syndromes - Data from the TERCET registry with 19,287 patients. Pharmacological research 2019, 139:460-466.

11. Guedeney P, Claessen BE, Kalkman DN, Aquino M, Sorrentino S, Giustino G, Farhan S, Vogel B, Sartori S, Montalescot G et al: Residual Inflammatory Risk in Patients With Low LDL Cholesterol Levels Undergoing Percutaneous Coronary Intervention. Journal of the American College of Cardiology 2019, 73(19):2401-2409.

12. Raposeiras-Roubin S, Rosselló X, Oliva B, Fernández-Friera L, Mendiguren JM, Andrés V, Bueno H, Sanz J, Martínez de Vega V, Abu-Assi E et al: Triglycerides and Residual Atherosclerotic Risk. Journal 
of the American College of Cardiology 2021, 77(24):3031-3041.

13. Vallejo-Vaz AJ, Fayyad R, Boekholdt SM, Hovingh GK, Kastelein JJ, Melamed S, Barter P, Waters DD, Ray KK: Triglyceride-Rich Lipoprotein Cholesterol and Risk of Cardiovascular Events Among Patients Receiving Statin Therapy in the TNT Trial. Circulation 2018, 138(8):770-781.

14. Chait A, Ginsberg HN, Vaisar T, Heinecke JW, Goldberg IJ, Bornfeldt KE: Remnants of the TriglycerideRich Lipoproteins, Diabetes, and Cardiovascular Disease. Diabetes 2020, 69(4):508-516.

15. Schwartz GG, Abt M, Bao W, DeMicco D, Kallend D, Miller M, Mundl H, Olsson AG: Fasting triglycerides predict recurrent ischemic events in patients with acute coronary syndrome treated with statins. Journal of the American College of Cardiology 2015, 65(21):2267-2275.

16. Toth PP, Granowitz C, Hull M, Liassou D, Anderson A, Philip S: High Triglycerides Are Associated With Increased Cardiovascular Events, Medical Costs, and Resource Use: A Real-World Administrative Claims Analysis of Statin-Treated Patients With High Residual Cardiovascular Risk. Journal of the American Heart Association 2018, 7(15):e008740.

17. Miller M, Stone NJ, Ballantyne C, Bittner V, Criqui MH, Ginsberg HN, Goldberg AC, Howard WJ, Jacobson MS, Kris-Etherton PM et al: Triglycerides and cardiovascular disease: a scientific statement from the American Heart Association. Circulation 2011, 123(20):2292-2333.

18. Ginsberg HN, Packard CJ, Chapman MJ, Borén J, Aguilar-Salinas CA, Averna M, Ference BA, Gaudet D, Hegele RA, Kersten $S$ et al: Triglyceride-rich lipoproteins and their remnants: metabolic insights, role in atherosclerotic cardiovascular disease, and emerging therapeutic strategies-a consensus statement from the European Atherosclerosis Society. European heart journal 2021.

19. Bhatt DL, Steg PG, Miller M, Brinton EA, Jacobson TA, Ketchum SB, Doyle RT, Jr., Juliano RA, Jiao L, Granowitz $\mathrm{C}$ et al: Cardiovascular Risk Reduction with Icosapent Ethyl for Hypertriglyceridemia. The New England journal of medicine 2019, 380(1):11-22.

20. Peterson BE, Bhatt DL, Steg PG, Miller M, Brinton EA, Jacobson TA, Ketchum SB, Juliano RA, Jiao L, Doyle RT, Jr. et al: Reduction in Revascularization With Icosapent Ethyl: Insights From REDUCE-IT Revascularization Analyses. Circulation 2021, 143(1):33-44.

21. Klempfner R, Erez A, Sagit BZ, Goldenberg I, Fisman E, Kopel E, Shlomo N, Israel A, Tenenbaum A: Elevated Triglyceride Level Is Independently Associated With Increased All-Cause Mortality in Patients With Established Coronary Heart Disease: Twenty-Two-Year Follow-Up of the Bezafibrate Infarction Prevention Study and Registry. Circulation Cardiovascular quality and outcomes 2016, 9(2):100-108.

22. Cordero A, López-Palop R, Bertomeu-González V, Carrillo P, Moreno-Arribas J, Bertomeu-Martínez V: Clinical profile and prognosis of patients with low-density lipoprotein cholesterol $<70 \mathrm{mg} / \mathrm{dL}$ and acute coronary syndrome. Revista espanola de cardiologia (English ed) 2013, 66(7):588-589.

\section{Figures}


2955 patients undergoing successful PCI and receiving statin therapy at discharge were screened

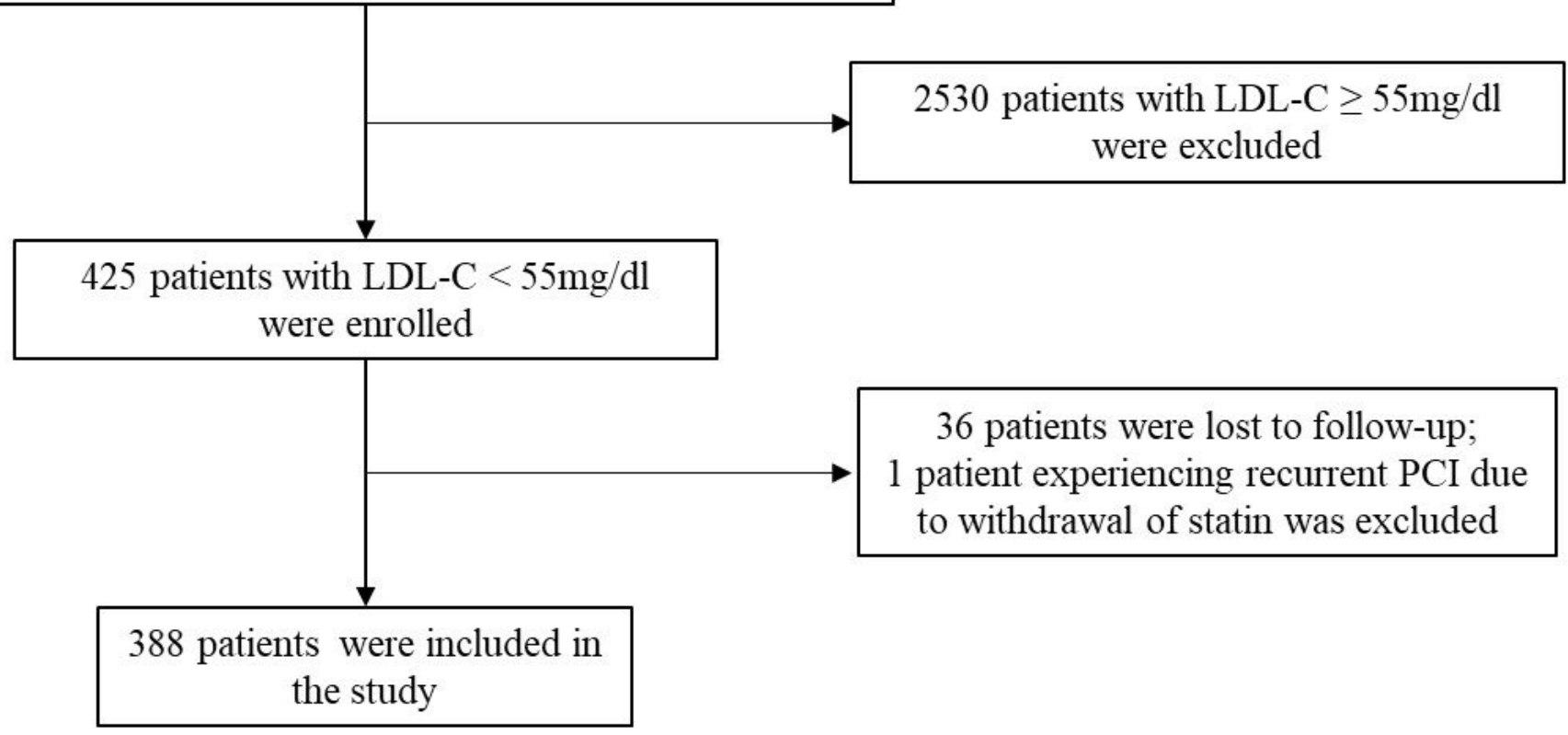

\section{Figure 1}

Study flowchart. 


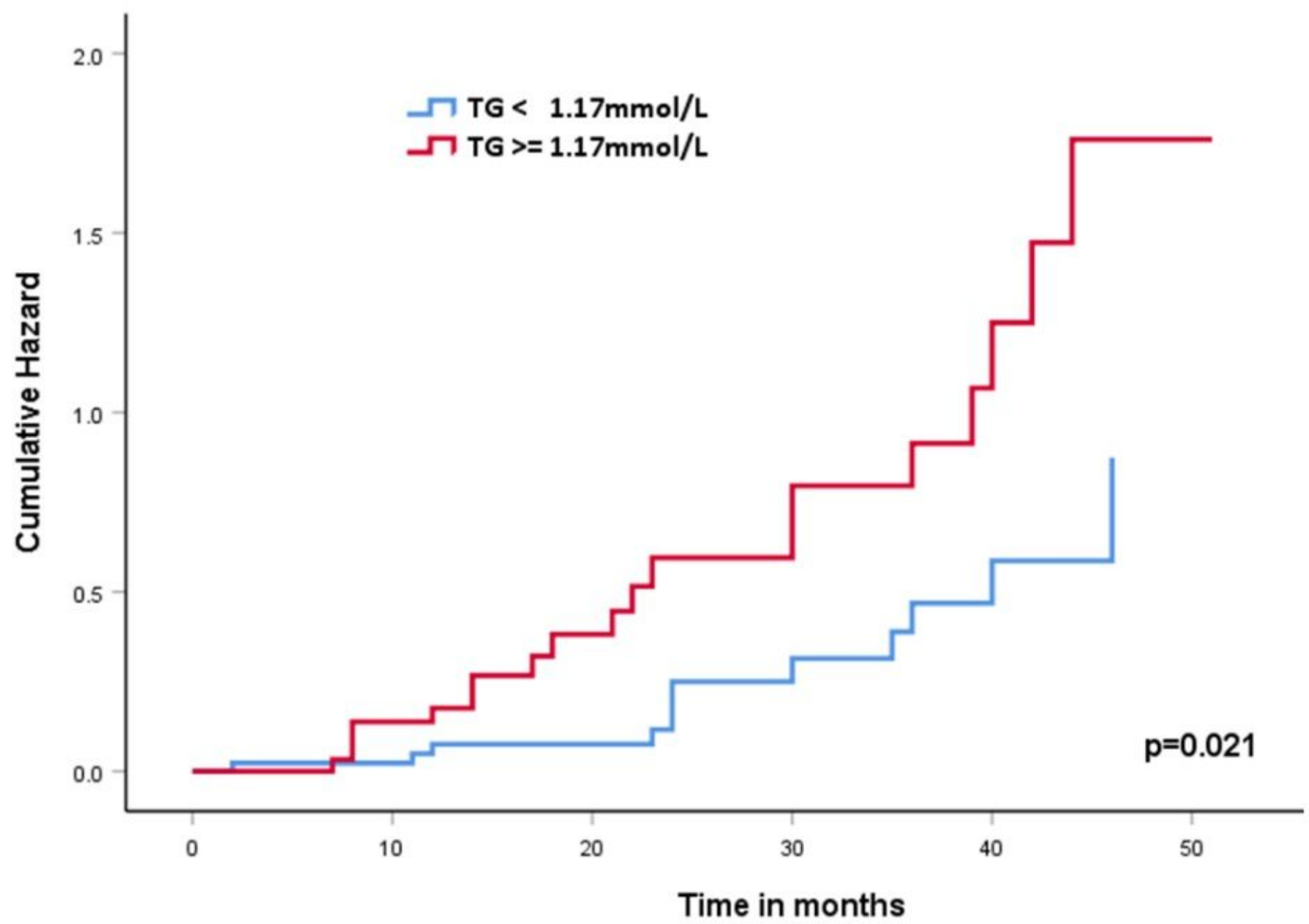

\begin{tabular}{|c|c|c|c|c|c|c|}
\hline \multicolumn{7}{|c|}{ Number at risk } \\
\hline $\mathrm{TG}<1.17 \mathrm{mmol} / \mathrm{L}$ & 246 & 241 & 228 & 217 & 210 & 48 \\
\hline $\mathrm{TG}>=1.17 \mathrm{mmol} / \mathrm{L}$ & 142 & 139 & 128 & 122 & 118 & 25 \\
\hline & 0 & 10 & 20 & 30 & 40 & To \\
\hline
\end{tabular}

\section{Figure 2}

Kaplan-Meier analysis demonstrated that a higher TG level $(\geq 1.17 \mathrm{mmol} / \mathrm{L})$ resulted in a higher risk of recurrent revascularization events than a lower TG level $(<1.17 \mathrm{mmol} / L)(p=0.021$ by log-rank test). 